\title{
Differences over 10 years in epidemiologic and clinical features of Kawasaki disease at a single tertiary center
}

\section{To the editor,}

Kawasaki disease (KD) is an acute systemic vasculitis of unnown etiology that affects infants and young children; approximately $80 \%$ of affected patients are under 5 years of age. ${ }^{1,2)}$ The epidemiology of $\mathrm{KD}$ shows typical characteristics regarding race (northeastern Asian children, including those in Japan, South Korea, and Taiwan, have a 10-20 times higher incidence than Caucasian children), sex (boys have a 1.3-1.5 times higher incidence than girls), age (about $80 \%$ are under 5 years of age), presence of siblings (relative risk in siblings is 10 times higher), and seasonal incidence (peaks in winter and summer), and KD usually presents as outbreaks (in Japan). ${ }^{3,4)}$ These epidemiological features and the current consensus in the scientific field suggest that the pathogenesis of $\mathrm{KD}$ is likely to be an abnormal immune response caused by an infectious trigger that develops in genetically predisposed children. ${ }^{1)}$

We researched the incidence, treatments, and coronary complications of KD in Keimyung University Dongsan Hospital in Daegu, Korea, between January 2009 and December 2018 and evaluated the differences over 10 years. This study was approved by the institutional review board of Keimyung University Dongsan Medical Center (approval number: 2019-07-047).

A total of 593 patients (357 boys, 236 girls) with KD were enrolled. The annual incidence of KD per 1,000 total admissions increased significantly over the 10-year period (standardization coefficient $[\beta]=0.821, R^{2}=0.612, P=0.002$ ). The total number of complete and incomplete $\mathrm{KD}$ cases increased over 10 years ( $\beta=0.784, R^{2}=0.615, P=0.007$ for complete $\mathrm{KD} ; \beta=0.904$, $R^{2}=0.818, P<0.001$ for incomplete KD) (Fig. 1).

In 16 patients (2.7\%), the fever and clinical signs sponta- neously resolved after admission without treatment; the other 577 patients (97.3\%) were treated with intravenous immunoglobulin (IVIG) $2 \mathrm{~g} / \mathrm{kg}$ as primary IVIG therapy (Table 1 ). The nonresponder rate to primary IVIG therapy was $24.6 \%$ (142 patients); second IVIG therapy was provided in 104 patients, intravenous methylprednisolone pulse therapy $(30 \mathrm{mg} / \mathrm{kg})$ in 35 , and oral prednisolone $(2 \mathrm{mg} / \mathrm{kg})$ in 3 as the second treatment regimen. For the third treatment, 16 nonresponders after the second repeat dose of IVIG received methylprednisolone pulse therapy and one nonresponder to methylprednisolone pulse therapy received infliximab. During the fourth treatment, one nonresponder to methylprednisolone pulse therapy from the third round received infliximab. Among the 593 patients, coronary artery disease (CAD) was detected in $103(17.5 \%)$ and a giant coronary aneurysm was seen in $4(0.7 \%)$. During this study period, the incidence of nonresponders to IVIG and CAD showed a decreasing trend over 10 years, although the difference was not statistically significant $\left(\beta=-0.249, R^{2}=-0.055, P=0.488\right.$ for nonresponders to IVIG; $\beta=-0.257, R^{2}=-0.051, P=0.473$ for

\section{Table 1. Treatment sequence}

\begin{tabular}{lcccc}
\hline Variable & First & Second & Third & Forth \\
\hline No treatment & $16(2 / 14)$ & - & - & - \\
$\begin{array}{l}\text { Intravenous immunoglo- } \\
\text { bulin }\end{array}$ & $577(238 / 339)$ & $104(33 / 71)$ & - & - \\
$\begin{array}{l}\text { Intravenous methylpredni- } \\
\quad \text { solone pulse therapy }\end{array}$ & - & $35(29 / 6)$ & $16(3 / 13)$ & - \\
$\begin{array}{l}\text { Oral prednisolone } \\
\text { Infliximab }\end{array}$ & - & $3(1 / 2)$ & - & - \\
& - & - & $1(0 / 1)$ & $1(1 / 0)$
\end{tabular}

Values are presented as total number (period 1/period 2).
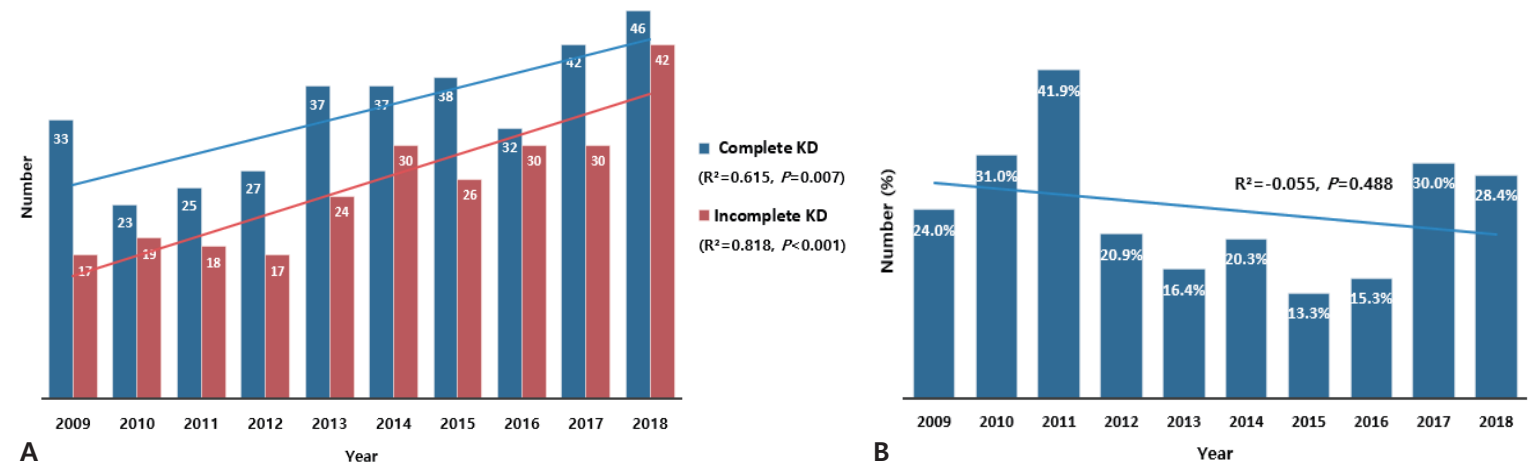

Fig. 1. The annual incidence of complete versus incomplete Kawasaki disease (KD) (A) and nonresponse to intravenous immunoglobulin during the study period (B). 
CAD) (Fig. 1).

According to a recent nationwide survey of $\mathrm{KD}$, its incidence significantly increases annually in South Korea (194.7-217.2/ 100,000 children $<5$ years of age in 2014) and in Japan (308/ 100,000 children $<5$ years of age in 2014). ${ }^{5,6)}$ Similarly, the incidence of $\mathrm{KD}$ in our study, especially incomplete $\mathrm{KD}$, showed annually an increasing trend. The increasing incidence of incomplete $\mathrm{KD}$ may be due to the use of the systemic diagnostic algorithm for diagnosing incomplete $\mathrm{KD}$ (from American Heart Association guidelines) as it helps clinicians easily diagnose incomplete $\mathrm{KD}$. The treatment sequence of acute $\mathrm{KD}$ was well established: generally, it involves IVIG as first treatment, a second repeat dose of IVIG as second treatment, steroids as third treatment, and infliximab as fourth treatment. ${ }^{1)}$ The treatment sequence of $\mathrm{KD}$ in our study showed a similar pattern. The overall response rate for first IVIG treatment in South Korea was $88.2 \%$, which was somewhat higher than that in Japan (71.6\%$83.0 \%)$ and in the US (83.7\%). ${ }^{6-8)}$ In our study, the response rate for first IVIG was $75.4 \%$, somewhat lower than the nationwide survey of South Korea. The incidence of nonresponse to IVIG showed a decreasing trend over time. Coronary artery dilatation occurred more often in our study than in the nationwide survey $(17.5 \%$ vs. $10.8 \%)$, whereas coronary aneurysm occurred less frequently in our study than in the nationwide survey $(0.7 \%$ vs. 1.7\%). ${ }^{6}$ As in previous studies, the incidence of CAD showed a decreasing trend over time.

Our study has some limitations. We retrospectively analyzed data through medical records in a single local hospital in Korea. There might be some differences in the results due to regional policies and individual preferences in patient management.

In conclusion, the incidence of $\mathrm{KD}$, especially incomplete $\mathrm{KD}$, presented an increasing trend, while the incidence of nonresponse to IVIG and CAD presented a decreasing trend over 10 years in our institution. At each institution, it is essential to create awareness of the importance of the epidemiological factors and clinical features of $\mathrm{KD}$ in the proper and timely management of patients to prevent coronary complications.
Hyun Su Kim, MD, Suk Won Shin, MD, Bo Geum Choi, MD, Hee Joung Choi, MD, PhD

Department of Pediatrics, Keimyung University Dongsan Hospital, Keimyung University School of Medicine, Daegu, Korea

Corresponding author: Hee Joung Choi, MD. Department of Pediatrics, Keimyung University Dongsan Hospital, Keimyung University School of Medicine, 1095 Dalgubeol-daero, Dalseogu, Daegu 42601, Korea

凶E-mail: joung756@dsmc.or.kr, https://orcid.org/0000-00027119-4194

Conflicts of interest

No potential conflict of interest relevant to this article was reported.

\section{References}

1. McCrindle BW, Rowley AH, Newburger JW, Burns JC, Bolger AF, Gewitz $\mathrm{M}$, et al. Diagnosis, treatment, and long-term management of Kawasaki Disease: a scientific statement for health professionals from the American Heart Association. Circulation 2017;135:e927-99.

2. Newburger JW, Takahashi M, Burns JC. Kawasaki disease. J Am Coll Cardiol 2016;67:1738-49.

3. Nakamura Y. Kawasaki disease: epidemiology and the lessons from it. Int $\mathrm{J}$ Rheum Dis 2018;21:16-19.

4. Singh S, Vignesh P, Burgner D. The epidemiology of Kawasaki disease: a global update. Arch Dis Child 2015;100:1084-8.

5. Makino N, Nakamura Y, Yashiro M, Sano T, Ae R, Kosami K, et al. Epidemiological observations of Kawasaki disease in Japan, 2013-2014. Pediatr Int 2018;60:581-7.

6. Kim GB, Park S, Eun LY, Han JW, Lee SY, Yoon KL, et al. Epidemiology and clinical features of Kawasaki disease in South Korea, 2012-2014. Pediatr Infect Dis J 2017;36:482-85.

7. Makino N, Nakamura Y, Yashiro M, Ae R, Tsuboi S, Aoyama Y, et al. Descriptive epidemiology of Kawasaki disease in Japan, 2011-2012: from the results of the 22nd nationwide survey. J Epidemiol 2015;25:239-45.

8. Moffett BS, Syblik D, Denfield S, Altman C, Tejtel-Sexson K. Epidemiology of immunoglobulin resistant Kawasaki disease: results from a large, national database. Pediatr Cardiol 2015;36:374-8. 